\title{
How Future Goals Enhance Motivation and Learning in Multicultural Classrooms
}

\author{
Karen Phalet, ${ }^{1,3}$ Iris Andriessen, ${ }^{1}$ and Willy Lens ${ }^{2}$
}

This review examines the impact of future goals on motivation and learning in multicultural classrooms. Across cultures, schooling is a future-oriented investment. Studies of minority students' school achievement have advanced future goals as a crucial protective factor in the face of frequent school failure. At the same time, cultural discontinuities and limited opportunities in minority students' school careers may weaken the motivational force of the future. Our review of the seemingly contradictory evidence on the role of the future in minority students'school achievement calls for a more fine-grained motivational theory of the future. Specifically, converging findings support conceptual distinctions (a) between positive and negative perceptions of the instrumentality of school tasks for future goals, and (b) between internal and external regulation of classroom behaviour by future goals. Thus, positive instrumentality and internal regulation enhance intrinsic motivation and adaptive learning in multicultural classrooms. We conclude that the motivational force of future goals can be generalized to minority students and that it depends crucially on perceived instrumentality and internal regulation.

KEY WORDS: future goals; multicultural classrooms; motivation; instrumentality.

\section{INTRODUCTION}

As a consequence of new non-European immigration from the 1960s until today, schools and classrooms in Western Europe, as in the United States, have become increasingly multicultural. From the late 1980s onward,

${ }^{1}$ Cross-Cultural Studies, Utrecht University, the Netherlands.

${ }^{2}$ University of Leuven, Leuven, Belgium.

${ }^{3}$ Correspondence should be addressed to Karen Phalet, Cross-Cultural Studies, Utrecht University, P.O. Box 80.140 Netherlands-3508 TC Utrecht, the Netherlands; e-mail: k.phalet@fss.uu.nl. 
when the second generation started their school careers, many European schools were for the first time confronted with an increasingly ethnically (i.e., racially, culturally, and linguistically) diverse student population. In the European context, we use the term migrant or minority youth interchangeably to refer to the children of first-generation ethnic minorities, who may or may not have the nationality of the host country. Predominant postcolonial and guest worker types of immigration in Europe occupy an intermediate position in between upwardly mobile voluntary immigrants and permanently excluded involuntary immigrants in the U.S. context of race relations (Ogbu, 1992). More often than not, the minority status of ethnic minority families in European host countries is associated with social disadvantage. This is especially true for children of so-called labor immigrants including, among others, Turkish and Moroccan youth in Europe (Vermeulen and Perlmann, 2000). Most often, their parents have a rural background with little or no formal education; they are vastly overrepresented in low-end jobs; and they are more often unemployed and living in relatively poor urban neighborhoods. As visible minorities, they are also facing widespread ethnic discrimination and prejudice by their European hosts (Bovenkerk et al., 1991).

Clearly, immigration has become a salient and a permanent feature of the school environment in European and North American cities. From an applied angle, the ensuing changes in the social and ethnic composition of student populations have far-reaching implications for educational psychology. Learning and teaching in multicultural classrooms pose a major challenge to both students and teachers. Teachers are facing the difficult task of providing an optimal learning environment to students from varying social, cultural, and linguistic backgrounds. From their side, minority students may have different experiences in the same classroom than their native classmates. For instance, they may have difficulty in understanding teacher instructions and in structuring school tasks, and hence use less effective learning strategies (Tharp, 1989). Not only task aspects but also relational and cultural aspects of the classroom environment come into play. For example, negative teacher stereotypes of minority students as lazy or dumb may become self-fulfilling prophecies (Steele and Aronson, 1995). Furthermore, repeated experiences of school failure may threaten the selfesteem of disadvantaged minority youth, leading to disengagement with learning (Okagaki et al., 1996). Some minority students may lack social or cultural skills to participate actively in classroom interactions (Connell et al., 1994). Others may actively oppose or resist schoolwork as a reaction against perceived ethnic discrimination by teachers or peers (Ogbu and Simons, 1998).

In view of the many social, cultural, and academic obstacles that minority students are likely to encounter on their way to school success, the 
question of which motivational factors may support minority students' school achievement is a crucial one. This review focuses specifically on the motivational force of future goals in multicultural classrooms, bringing together cross-cultural motivational research in the United States and Europe. It is argued that the future is both highly relevant and of prime importance for school achievement in general, and for the achievement of minority students in particular.

In the first part of this review, we discuss mixed evidence from crosscultural studies on the motivational role of the future in sustaining minority students' school engagement and achievement. Specifically, frequent findings of "resistance to schooling," in spite of high aspirations or future expectations, cast doubt on the motivational force of the future in minority students' school careers. Typically, school failure is attributed to a lack of congruence between home and school cultures, or else to limited opportunities for disadvantaged minority youth.

The second part builds on recent developments in motivational research on future time perspective and goal theory, with a view to developing and documenting a more fine-grained motivational theory of future goals. It is argued that future goals may fail to motivate school achievement for two main reasons: Because students may not perceive a clear positive connection between doing well in school and success later in life; and because they may not experience future goals as internally driven or self-set goals but rather as externally controlled or imposed from the outside. Extending recent motivational research to minority students' school achievement, we conclude that future goals will motivate achievement in multicultural classrooms, provided that schools and families succeed in fostering internal regulation along with positive perceptions of instrumentality.

\section{THE ROLE OF THE FUTURE IN MINORITY STUDENTS' SCHOOL CAREERS}

Across cultures, schooling is not an end in itself. It is a future-oriented investment. Whereas learning and achieving good grades may be rewarding as such, they are also important to achieve highly valued educational or professional career goals in the future. Hence, students who are highly motivated to achieve in school are probably also highly involved in their future educational and professional career (Husman and Lens, 1999). Turning to the schooling experience of minority students, future goal setting acquires special relevance as a psychological buffer against more frequent school failure and dropout (Meece and Kurtz-Costes, 2001). In general, future goals sustain achievement motivation in the face of failure by turning attention 
away from past or present setbacks to possible improvement or progress in the future (Nuttin and Lens, 1985). In minority students' school careers in particular, a strong and positive future orientation seems crucial to succeed. Although a majority of nonethnic minority youth may pass with considerably more ease and less motivation, most minority children start their school career with an initial disadvantage and hence must work harder and persist more to catch up with their native classmates. Two types of evidence lend support to the role of the future in the minority students' school careers: (a) cross-cultural studies have documented the subjective importance of future goals in the schooling experience of minority youth (Zéroulou, 1998); (b) there is indirect as well as direct evidence of the impact of future goal setting on minority students' school success (Okagaki and Frensch, 1998).

\section{Importance and Impact of the Future: The Immigrant Optimism Hypothesis}

In support of the importance of the future, ethnic minorities in the United States and Europe are revealed as strong believers in self-improvement through academic achievement. Compared with native parents with a similar social-class background, ethnic minority parents typically express higher aspirations and a more academic orientation toward nonvocational secondary and higher education for their children (Müller and Kerbow, 1993; Vallet and Caille, 1996). In a similar vein, ethnographic studies of minority families and communities have documented high aspirations in ethnic minority families and youth as part of an intergenerational social-mobility project (Matute-Bianchi, 1986; Suarez-Orozco and Suarez-Orozco, 1995; Zéroulou, 1998). In the European host context, newcomers are often reluctant ethnic minorities who hope to better themselves in the short run and to return to their countries of origin. Settled ethnic minority communities, however, tend to reorient their socioeconomic immigration project toward a better future in the host society (Zéroulou, 1998). In Europe as in the United States, minority parents typically perceive educational investment in the children as the primary means to improving the family's living standards and socioeconomic status. From their side, minority youth often perceive educational progress as a family obligation and as an effective way to achieve a better future (Matute-Bianchi, 1986; Suarez-Orozco and Suarez-Orozco, 1995).

A series of cross-cultural motivational studies provide converging evidence of the importance of future expectations in ethnic minority families for the school achievement of minority students. Thus, in their crosscultural study of Turkish and Belgian youth, Phalet and Claeys (1993) found that Turkish immigrant students were more achievement oriented than 
native Belgian students of the same social class. Similarly, a recent study by Andriessen and Phalet (2002), comparing motivation and learning among Turkish, Moroccan, and native students in Dutch high schools, reveals higher levels of task motivation and engagement with learning, along with more positive feelings of school belonging, for ethnic minority students than for lower class native students. Last, Phalet et al. (2001) have measured separately the levels of future and present task motivation in Turkish, Moroccan, and native students. Their questionnaire measure of future goals includes personal maturity, career goals, and later earnings or material rewards. In comparison with their native classmates, minority students attach more importance to reasons for studying that are located in the distant future.

Turning to the future expectations of ethnic minority parents, there is mixed evidence of family-based educational investment in the school careers of the second generation. Thus, comparative studies on Turkish, Moroccan, and native Dutch families report higher academic aspirations among ethnic minority parents than among native parents with a similar social background (Nijsten, 1998; Pels, 1998). At the same time, the generally high value attached to education by ethnic minority parents is often accompanied by perceptions of ethnic prejudice and culture conflict in Dutch schools, suggesting at least some degree of ambivalence in parental attitudes toward schooling. Moreover, these findings leave unanswered the key question in how far parental values and aspirations effectively motivate school achievement in their children. In two comparative studies with ethnic minority parent-child dyads in Germany and in the Netherlands, Phalet and Schönpflug (2001a,b) addressed precisely this question. Although both studies support the successful transmission of family values of relatedness to the next generation, the evidence is less clear-cut for achievement goals and aspirations. They conclude that the effective transmission of parental aspirations varies with educational opportunities in the host context. Overall, cross-cultural studies in the United States and Europe suggest that parental aspirations may, at least in some cases, successfully motivate the school achievement of ethnic minority youth.

Not only are many ethnic minority families and youth more aspiring than lower class native families, high aspirations and future expectations appear to predict educational attainment (e.g., Okagaki and Frensch, 1998). Thus, there is indirect evidence from national longitudinal studies of educational progress, in the United Kingdom (Smith and Tomlinson, 1989), France (Vallet and Caille, 1996), and Australia (Clifton et al., 1991). Across host societies, the findings document an initial educational disadvantage of minority children in comparison with native classmates. This is followed, however, by greater progress among minority students, leading to delayed attainment toward the end of secondary school. Apparently, sustained achievement 
motivation in the face of failure enables at least some portion of minority youth to make progress over time and in the end to catch up with native classmates.

Although such indirect findings are suggestive of the motivational force of a positive future orientation, there is also more direct evidence. Thus, longitudinal studies in France and Australia find positive effects of parental aspirations on the educational progress of minority and nonminority children alike, after controlling for social and family background (Clifton et al., 1991; Vallet and Caille, 1996). Apparently, children of more aspiring minority parents are more likely to be successful in school. Similarly in the United States, students who believe that doing well in school is instrumental for their future careers are more successful in school (Steinberg et al., 1992). Accordingly, a multiethnic study of minority youth shows positive effects of parental academic aspirations and future expectations on the school performance of their children. These motivational effects hold after controlling for previously obtained grades (Okagaki and Frensch, 1998). Other studies in the United States have addressed the development of future goals in disadvantaged minority youth. For example, a study of Mexican American youth emphasized the utility of good grades in school to overcome social disadvantage and poverty (Day et al., 1994). Similarly, in a follow-up study of African American Head Start children, educational goal setting was revealed as the critical juncture between early school experience and later educational attainment (Slaughter-Defoe and Rubin, 2001). In parallel, Turkish and Moroccan minority students in Dutch schools were asked to report their perceptions of the instrumental value of schooling for success later in life (Phalet and Andriessen, in press). As expected, minority students with more positive perceptions of instrumentality achieve higher levels of educational attainment and progress (when the latter measure is controlled for initial school advice). More importantly, the impact of students' future orientation is significant after taking into account family background and ethnic composition of schools.

These and other findings of close linkages between immigration, future orientation, and school achievement gave rise to the well-known immigrant optimism hypothesis, which attributes educational progress in minority youth to parental expectations of upward intergenerational mobility through education (Kao and Tienda, 1995). In other words, the typical striving of minority families for upward mobility in a distant future motivates the school achievement of minority children. Three possible explanations have been advanced to account for the self-fulfilling prophecy of immigrant optimism (Vallet and Caille, 1996). First, immigration is associated with the positive selection of more aspiring persons, because persons with a weak motivational drive are less likely to leave behind the comforts of home in search 
of a better future. Second, the lack of schooling in most minority families is due to failing school systems in the countries of origin. In the absence of a history of school failure, therefore, ethnic minorities with little or no schooling are more likely to attach positive value to school achievement than sections of the host population with similarly low levels of education. Finally, the relative overinvestment in education that sets minorities apart from the native working classes may also be motivated by the realistic anticipation of ethnic discrimination in the labor market. Thus, ethnic minorities may perceive schooling as an effective means to overcome discrimination. Whatever the mechanisms that connect minority status with future-oriented educational investment, the empirical evidence leads us to a double conclusion. Across cultures, minority students, and their parents, typically express high levels of future goal orientation, as compared with lower class native students. Moreover, those students, minority as well as native, who are more oriented toward future goals, show enhanced levels of classroom motivation and achievement.

To conclude, the immigrant optimism hypothesis highlights the motivational importance and impact of future goals. It explains why some minority students succeed in school despite their initial disadvantage, and why so many of them continue to be highly motivated in the face of failure in school. In this latter respect, ethnic minority students differ markedly from their generally less motivated native classmates with a lower class background. On a cautionary note, some findings suggest that there are limits to the motivational impact of high parental aspirations in the presence of perceived discrimination or unequal opportunities (Pels, 1998; Phalet and Schönpflug, 2001b). Moreover, the findings in support of immigrant optimism do not include so-called involuntary minorities in the U.S. context (Ogbu, 1992). More in general, the immigrant optimism hypothesis has been challenged by conflicting findings from research on the role of perceived opportunities in minority students' school careers. This type of research focuses on class and race barriers that stand in the way of minority students' school achievement (Ogbu, 1992).

\section{Perceived Opportunities: The Attitude-Achievement Paradox}

Research from a perceived opportunities approach has challenged the psychological viability of future-oriented achievement motivation under conditions of severe disadvantage and discrimination. Although academic aspirations are a good predictor of successful achievement most of the time, they often fail to predict achievement in disadvantaged minority youth. Specifically, studies among African American youth in the United States 
have repeatedly found conflicting evidence of low levels of school achievement, in spite of high levels of motivation to achieve upward mobility through schooling (Ogbu and Simons, 1998). This repeated finding is labelled the attitude-achievement paradox. This paradox is commonly explained as a result of ambivalent attitudes toward achievement in the presence of racism and discrimination (Mickelson, 1990).

There are three major sources of evidence from educational research that associate limited opportunities with detrimental motivational processes. First, most African American and Latino youth are found to endorse "abstract" mobility beliefs about the value of education for success later in life. At the same time, however, they tend to reject "concrete" beliefs about the benefits of education for their personal future (Mickelson, 1990). The discrepancy between abstract and concrete mobility beliefs is instructive because it suggests limits to the perceived instrumentality of doing well in school in the absence of sufficient opportunities. In a similar vein, Phalet and Claeys (1993) found that highly unequal educational opportunities in Turkey are associated with low achievement expectations among urban youth, in spite of typically high levels of commitment to present and future achievement goals, as compared with urban youth in Belgium. The observed discrepancy between achievement values and expectations in the future orientation of Turkish youth is reminiscent of Mickelson's attitude-achievement paradox in the U.S. context. Last, a wide stream of research has associated racism and discrimination in the classroom with impaired performance and so-called resistance to schooling in minority students (Okagaki et al., 1996). When the school environment thus fails to support minority achievement, minority students may develop ambivalent or negative attitudes toward school achievement. Even in the case of more aspiring ethnic minority families, negative peer pressure or low teacher expectations may result in situationally induced disengagement with learning (D'Amato, 1993). Resistance to schooling in disadvantaged minority youth has been associated with three types of explanatory factors: (a) poor school adjustment (Okagaki et al., 1996), (b) identity conflict (Arroyo and Ziegler, 1995), and (c) stereotype threat (Steele, 1997).

Thus, from the perspective of school belonging and psychological adjustment (Goodenow and Grady, 1993; Roeser et al., 1996; Voekl, 1996), perceptions of ethnic or racial barriers in peer interactions and teaching practices may interfere with the school adjustment of minority students. Accordingly, students who experience ethnic discrimination in class are more prone to resist schoolwork. For instance, Latino children who agree that "it is harder for Latino kids to get good grades from teachers" are paying less attention and working less diligently in class than those who believe that "Latino kids can get good grades as easily as white kids" (Okagaki et al., 1996). 
A related explanation of resistance to schooling has focused on identity conflict. Specifically, the controversial acting white hypothesis (cf. Fordham and Ogbu, 1986) builds on ethnographic evidence of oppositional ethnic identification. The development of an oppositional identity, and the ensuing motivational conflict between ethnic loyalty and school success, is understood as a reaction against ethnic prejudice in school. The acting white hypothesis has, however, been challenged by mixed evidence of either positive or zero correlations between ethnic self-identification and school achievement. Thus, a recent large-scale study in the United States finds that afrocentric self-identity is positively related to academic self-esteem and achievement (Spencer et al., 2001). Similarly, a cross-cultural study of ethnic minority students in vocational and higher tracks of Dutch high schools finds that ethnic minority youth who feel more strongly involved with their ethnic identity show higher levels of educational progress than more weakly identified peers (Phalet and Andriessen, in press). But a twin study of ethnic relations in Dutch multicultural classrooms finds no significant correlation between ethnic identity and school achievement within the same educational track (Verkuyten and Canatan, in press). Looking across various immigrant communities and host societies (including the United States, the Netherlands, Finland, and Israel), comparative research by Phinney et al., (2001) yields weak or inconsistent associations of minority students' school adjustment with ethnic identification, along with much more robust positive associations of school success with national identification (with the host country). The authors conclude that the development of a bicultural identity, combining ethnic and national attachments, is most conducive to minority students' school success. Conversely, conflictual ethnic relations, opposing ethnic and national loyalties, has a negative impact on school success.

Finally, a series of studies on stereotype threat have specified when and how concerns with self-identity negatively affect school achievement (Steele, 1997). More precisely, ethnic and gender identity inhibit academic performance in experimental task situations where negative stereotypes are made salient and self-relevant (Spencer et al., 1999; Steele and Aronson, 1995). In contrast, positive stereotypes facilitate academic performance. Thus, among Asian American female undergraduates, the priming of ethnic identity yields higher math scores, whereas the priming of gender identity results in lower math scores (Shih et al., 1999). To conclude, ethnic or racial barriers interfere with academic achievement, when salient negative ethnic stereotyping by teachers or peers coincides with high ethnic self-identification by minority students.

Overall, research from a perceived opportunities perspective provides converging evidence of an attitude-achievement paradox, which contradicts the immigrant optimism hypothesis under conditions of enduring 
disadvantage. Specifically, minority students tend to develop ambivalent orientations toward the future in the face of unequal or blocked opportunities, as shown by research on abstract mobility beliefs and low future expectations. Moreover, experiences of ethnic conflict or racial exclusion in the classroom are shown to impede minority motivation and achievement, as is evident from research on resistance to schooling.

So far, we have discussed negative motivational effects of blocked opportunities, racism, and discrimination. To complete the picture of conflicting motivational forces in minority students' school careers, we now turn to alternative cultural explanations of motivation and achievement. Cultural forces in minority students' school careers have been studied along parallel research lines in multicultural classrooms and in minority families. On the one hand, minority students may experience more or less discontinuity between home and school cultures. Accordingly, cultural distance and acculturative adjustment problems in school are associated with resistance to schooling in minority youth (Jacob and Jordan, 1993). On the other hand, some minority families and communities are more forward-looking and more resourceful than others, and hence better equipped to overcome cultural distance and social disadvantage (Portes and MacLeod, 1996).

\section{Cultural Difference: Discontinuity Between Family and School Contexts}

Educational psychologists and anthropologists have long attributed socalled resistance to schooling in minority youth to cultural discontinuities between home and school environments. Obviously, resistance to schooling is not limited to minority students. Rather, there are inherent constraints in all forms of schooling, such as its compulsory and public nature, that evoke resistance in some students regardless of their social and cultural backgrounds (Arroyo and Ziegler, 1995). Still, minority children may experience more difficulty in engaging with their schoolwork, when behavioral norms and repertoires in class differ greatly from familiar norms and practices at home. This is the case when minority cultures are characterized by a normative emphasis on collectivism or relatedness, in contrast with dominant cultural values of individualism or separateness in the host culture (Phalet and Swyngedouw, in press). Consequently, ethnic minority students with a collectivist cultural background may have to cope with conflicting goal stresses in family and school contexts (Maehr and Nicholls, 1980). For example in the United States, strong norms of cooperation and sharing among Native American children are at odds with predominant competitive goal stresses in mainstream classrooms. This lack of congruence between the norms and values of home and school inhibits classroom 
participation (Greenbaum, 1985). Moreover, small changes in instructional practices can greatly facilitate adaptive learning in minority children. Thus, the introduction of small group learning improved the school achievement of Hawaiian children (Jordan, 1984). This classroom arrangement is more similar to the home environment, which is structured around child-initiated activity in peer groups of siblings and friends.

In spite of such successful experiments, the importance of cultural similarity between home and school contexts should be qualified in at least two ways. First, motivational studies of cooperative classrooms strongly suggest that cultural similarity per se may be less important than the culture-general adaptive value of cooperative learning. Across cultures, classroom arrangements facilitating cooperative learning are more effective in supporting motivation and achievement than individual or competitive goals structures (Ames and Archer, 1988; Gallimore, 1981; Johnson and Johnson, 1985). For example, Phalet and Lens (1995) found the highest levels of psychological adjustment and task performance among Turkish and Belgian students who were most strongly committed to both task goals and group goals.

Second, the cultural-difference approach is complicated by empirical findings from acculturation studies in multicultural classrooms (Andriessen and Phalet, 2002). Cultural explanations of minority underachievement typically treat cultural similarity or difference as exogenous factors. In contrast, acculturation research conceives of psychological cultural distance as a function of acculturation processes (Berry, 2002). Although most acculturation studies are primarily concerned with the impact of cross-cultural contact on ethnic minority well-being and health, a growing number of studies include cultural competence and school performance as relevant outcomes (Van de Vijver and Phalet, in press). Thus, minority students with high levels of bicultural competence experience less psychological distance or difficulty in cross-cultural encounters (Lafromboise et al., 1993). In addition to culture learning, migrant attitudes toward culture maintenance and culture contact also play a role (Berry, 2002). Among ethnic minority youth in the Netherlands, Phalet and Andriessen (in press) found that combined positive attitudes toward ethnic and host cultures in the school context contributed most to educational progress, in line with a most adaptive "integration" type of acculturation (Berry, 2002). Moreover, the impact of acculturation attitudes on school results remains significant after controlling for family background and ethnic composition of schools. In sum, acculturation research suggests that the facilitation of cross-cultural contact and learning in multicultural classrooms is crucial to support the school adjustment and achievement of minority students.

To conclude, empirical studies in multicultural classrooms have associated cultural difference or discontinuity with increased resistance to 
schooling in minority students. On the positive side, there is complementary evidence of the positive motivational impact of classroom arrangements that increase the cultural congruence between behavioral norms and repertoires at home and in school. Still, the role of cultural congruence in minority students' school achievement should not be overstated. Across cultures, minority students are better off when classroom interactions and teaching practices encourage cooperative learning and cross-cultural contact.

\section{Cultures of Success: Educational Investment in Minority Families}

A complementary type of cultural explanations has focused on cultural norms and practices in the family context, which may affect minority students' school achievement. Cross-cultural studies of minority families have amply documented the cultural diversity of parental mobility beliefs and achievement expectations (Kagitcibasi, 1990). Extending the motivational concept of personal investment (Maehr, 1984), the term "family investment" is used here to refer to a broad set of cultural values, beliefs, and behavioral practices within minority families and communities that motivate and support educational attainment. In psychological and anthropological studies, family investment was found to attenuate resistance to schooling in more "successful" minority groups (Gibson, 2000; Okagaki, 2001). Clearly, in some minority communities parents are more aspiring, and youngsters are more achieving, than in others. Thus, Portes and MacLeod (1996) found that relatively successful Cuban and Vietnamese communities in the United States mobilize more educational support than more disadvantaged Haitian and Mexican communities, after controlling for social class and immigration history. In parallel, Steinberg et al. (1992) found that generally less successful African American and Hispanic students report less educational support from parents and peers than more successful Asian and White students do.

Other more small-scale studies in the United States and Europe have similarly reported positive effects of family investment on the school achievement of immigrant or minority children (Okagaki and Frensch, 1998; Nijsten, 1998; Pels, 1998; Schneider and Lee, 1990). Concretely, family investment may consist of direct as well as indirect forms of help and encouragement from parents and siblings (Crul, 1999). Because many minority parents have little or no education and may not be familiar with the school system in the host society, parental support most often takes an indirect form. For example, Hieshima and Schneider (1994) found that Japanese parents in the United States, while they may not be able to help their children with their homework or to give specific instructions, find other, more indirect ways of promoting future success through hard work and high standards. Thus, 
they typically create a home environment that instils discipline and facilitates studying, encouraging their children to take private classes in music, language, or computer science, and to spend much time practicing for their lessons.

One possible explanation of cultural differences in family investment and school success refers to differential ethnic resources, such as family networks and mutual support (Portes and MacLeod, 1996). From a sociological viewpoint, communities that are more resourceful are more likely to lend effective support to high academic aspirations and achievement. Anthropological studies have similarly emphasized the role of family and community investment in minority students' school achievement, playing out cultural beliefs and values against structural disadvantage as competing explanatory grounds (Vermeulen and Perlmann, 2000). A useful synthesis of the interplay of cultural and structural factors in minority education is Ogbu's wellknown distinction between involuntary and voluntary types of minorities in the United States (Ogbu, 1992). To account for ethnographic observations of achievement in adversity among the latter type of minorities, he introduces the key concept of "folk models of success." Folk models refer to cultural ideals rooted in the shared history of a particular community that explain high academic aspirations in successful minorities.

Along those lines, there is much cross-cultural evidence showing that the perception of culturally relevant benefits to education positively affects minority students' school engagement and achievement. Examples include moral definitions of a good person as an educated person, as is the case in the Punjabi Sikh community (Gibson, 2000). Other examples refer to cultural notions of academic achievement as a source of family honor or prestige, for instance, in Asian American communities (Schneider and Lee, 1990). Across cultures, the culturally valued benefits attached to educational attainment differ considerably, ranging from moral virtue, honor to the family, a better marriage partner, to purely economic rewards (Okagaki, 2001). Overall, folk models refer to shared cultural ideals of self-improvement or status achievement through hard work and perseverance in spite of obstacles. Such cultural values and beliefs provide a supportive family context where the motivation to achieve is high, where effort and hard work are rewarded, and where parents feel responsible for the school success of their children (Hieshima and Schneider, 1994).

Similarly in a European host context, Phalet and Claeys (1993) found that Turkish ethnic minority youth, as compared to native youth, attached more value to present and future achievement goals. Parallel findings of family-based achievement striving among Turkish youth reflect broadly shared cultural values in a modernizing culture of relatedness (Gailly, 1979; Kagitcibasi, 1990; Phalet and Lens, 1995). Accordingly, Phalet and Lens 
(1995) found evidence of a family-oriented type of achievement motivation in Turkish youth, which pairs a strong sense of family loyalty with high academic aspirations. Moreover, cross-cultural causal models in Turkey and Belgium demonstrate the adaptive impact of relatedness and achievement goals, which enhance psychological adjustment and task performance. More in general, these findings resonate with cross-cultural evidence of a most frequent and adaptive collectivist type of achievement orientation in Asian cultures, as distinct from a predominant individualistic type of achievement motivation in the West (Maehr and Nicholls, 1980; Yu and Yang, 1994). In support of the psychological relevance of a collectivist achievement motive for minority youth, Phalet and Hagendoorn (1996) found that socioeconomic disadvantage was accompanied by sustained achievement striving, along with an increased emphasis on family loyalty among Turkish youth. Cultural distance between families and schools, however, appeared to weaken motivation and achievement in Turkish ethnic minority youth, as compared with lower class Turkish youth in Turkey, in spite of strong family ties. Apparently, there are limits to the adaptive value of family-based achievement striving when social disadvantage is coupled with large cultural distances in international immigration. Taken together, the Asian and Turkish examples in the United States and Europe strongly suggest that close-knit and forward-looking minority families may, at least to some extent, effectively support their children to succeed in spite of limited opportunities.

In summary, cross-cultural findings in family and school contexts lead to the following conclusions on the role of the future in minority students' school careers. On the one hand, high future expectations of minority parents and youth may fail to produce the desired school results, when cultural discontinuity with the school context leads to disengagement with learning. On the other hand, family investment may effectively support school achievement in spite of cultural discontinuity, when shared cultural values and beliefs within minority families and communities elevate the future benefits of schooling. To conclude, the immigrant optimism hypothesis holds in some cultural contexts but not in others; specifically, it holds when teaching practices and interactions in multicultural classrooms support cultural congruence and cooperative learning, and/or when shared cultural values and beliefs in minority families and communities promote educational investment.

\section{FUTURE GOALS, MOTIVATION, AND LEARNING}

\section{What Have We Learned? From Cultural Diversity to Common Processes}

So far, the cross-cultural literature leaves us with seemingly contradictory findings on the enhanced versus impaired role of future goals in minority 
students' school achievement. Probably the most important finding from the literature is that the schooling experience of minority youth is the product of conflicting motivational forces. On the positive side, high hopes of a better future through schooling seem inherent in the immigration project of many immigrant families (Kao and Tienda, 1995). Moreover, in some immigrant communities, such hopes are reinforced by shared cultural ideals, associating educational progress with collective achievement values (Phalet and Lens, 1995; Portes and MacLeod, 1996). At the same time, however, limited opportunities and cultural discontinuities constitute powerful negative incentives, which may stand in the way of minority students' school achievement (D'Amato, 1993; Mickelson, 1990). Hence, minority students run high risks of being caught between dreams and deeds.

Although it appears that future goals are highly relevant and influential in the schooling experience of minority youth, it is much less clear when and how future goals will effectively support motivation and learning. A major limitation of much research on the schooling of minority youth is its one-sided focus on motivational deficits or differences that set minority students apart from the mainstream (Meece and Kurtz-Costes, 2001). Hence, little is known about the cross-cultural validity of common motivational processes that may sustain, enhance, or undermine student motivation in multicultural classrooms. How do limited perceived opportunities and experienced cultural discontinuities affect motivation and learning among minority students? To improve our understanding of the seemingly contradictory cross-cultural findings reviewed above, we must spell out the motivational processes that connect future goals with classroom engagement and achievement. To this end, a more fine-tuned conceptual framework is needed. The following briefly discusses recent developments in motivational research regarding the future's impact on minority students' school achievement.

Goal striving is by definition future-oriented. Still, it is necessary to distinguish between immediate and delayed goals that play a role in academic achievement. Once immediate task goals and future goals are clearly distinguished, we can articulate how they are (dis)connected through time. This is an important explanatory task because the motivational impact of the future depends crucially on the processes that connect task goals in the present time with more distant future goals. To this end, a motivational framework is developed that brings together recent research in the areas of future time perspective, intrinsic motivation, and goal theories in the United States and Europe. Specifically, we argue and document two important conceptual distinctions: (a) a distinction between incentive value and instrumentality and (b) a further distinction between internal and external types of instrumentality. Finally, the key concepts of perceived instrumentality and internal regulation are brought to bear on minority students' school achievement. 


\section{Perceived Instrumentality, Motivation, and Learning}

Most research on achievement motivation in academic settings is limited by its one-sided focus on immediate goals in the present task situation and, consequently, by its neglect of the personal and instrumental relevance of delayed goals in the near or distant future. With a view to extending research on student motivation to include future time perspective (FTP), an important question concerns the development and impact of instrumental motivation: does the instrumentality of present task goals in terms of future goal setting make a difference in student motivation and learning?

According to Nuttin and Lens (1985), "future time perspective evolves from motivational goal setting. It is formed by more or less distant goals that are processed by the individual" (p. 22). Thus, formulating motivational goals in the distant future creates an extended FTP, which in turn strengthens the motivation to strive for those goals (Lens, 1986; Nuttin and Lens, 1985). To explain the motivational effects of a more or less extended FTP, De Volder and Lens (1982) distinguished between cognitive and dynamic aspects of FTP. Whereas the cognitive aspect of FTP refers to the instrumentality or utility value of immediate task goals to reach distant future goals, the dynamic aspect concerns the incentive value of more or less distant future goals. Specifically, the cognitive aspect refers to the capacity to anticipate in the present not only the immediate, but also the potential longterm consequences of one's actions. Students with a long FTP more easily anticipate the implications of their present classroom activities for the more distant future and elaborate on the covert level more long-term behavioral means-end structures, such as academic or professional plans or projects (e.g., a college degree or becoming a teacher). Therefore, the utility value or the instrumentality of present learning and achievement tasks in school is higher the longer the FTP. In addition, the dynamic aspect of FTP is defined as the preference to attribute a high valence to future goals, even if they are located in the more distant future. In general, the incentive value of a given reward decreases as a function of the length of its temporal delay (Mischel, 1981). This decrease is less steep, however, for persons with a long FTP than for those with a short FTP (De Volder and Lens, 1982). Because a long FTP reduces the psychological distance toward delayed goals, the incentive value of chronologically distant goals is higher the longer the FTP. More precisely, the effect of individual differences in the extension of FTP on the incentive value of future goals is curvilinear, so that it is smaller for goals in the very near or very distant future than for goals in the intermediate future.

From empirical research on expectancy $\times$ value theories (VIE) in motivational psychology (Feather, 1982), we know that people are more motivated when (a) they have higher expectations that their behavior will 
produce the desired outcomes (instrumentality) and (b) the subjective value of the outcomes is higher. Accordingly, a series of studies among nonminority students supports the positive motivational impact of the perceived instrumentality of school tasks for reaching future career goals, over and above the incentive value attached to present and future goals. De Volder and Lens (1982) indeed found a positive correlation between students' total motivation (Grade 11) and the length of their FTP. More motivated students attach more valence to goals in the distant future than less motivated students do. Many motivated students also attach more instrumental value to their schoolwork for reaching goals in the near and the distant future. In their study of student motivation in Flanders (Belgium), Lens and Decruyenaere (1991) categorized high school students in high, medium, and low motivation subgroups using a questionnaire measure of achievement motivation. Students with higher and lower motivation differed significantly in the instrumentality or utility value of "doing your best in school" for success in life in general. Thus, the more highly motivated students also attach the highest instrumental value to their schoolwork. Similarly, Van Calster et al. (1991) found that perceived instrumentality affects student motivation. Students in Grades 11 and 12 who perceive their schoolwork as important for their future (i.e., high instrumentality) are more motivated than students who experience education as less important (i.e., low instrumentality). But they also found an interaction effect between perceived instrumentality and affective attitudes toward one's individual future. Perceived instrumentality does enhance student motivation but only for students with a positive attitude toward their personal future. For students with a negative outlook on their future, attaching high utility to school results had the opposite effect on their motivation to study. In sum, the combination of a high level of perceived instrumentality and a positive attitude toward the personal future has a positive effect on student motivation and school results. Finally, Creten et al. (2001) studied the motivational role of perceived instrumentality or utility in vocational schools in Flanders (Belgium). Many students in vocational training have serious motivational problems, especially in studying theoretical courses such as mathematics, languages, and history. As compared to students in higher tracks, these students are often characterized by a rather short FTP (Lens and Decruyenaere, 1991). In other words, they do not clearly perceive, or do not much care about, the instrumentality or utility of present school tasks for their future career. As expected, Creten et al. (2001) found a positive correlation between the perceived instrumentality of theoretical and practical courses and student motivation for both types of courses. Although the studies are correlational, there is enough empirical evidence to conclude here that the instrumentality aspect of FTP increases the strength or intensity of student motivation for school tasks. 
Not only does the instrumental value of school tasks enhance student motivation, it also contributes to more effective learning strategies and better school results. Learning is the complex process of assimilating, structuring, and applying new knowledge and skills. As students play an active role in learning and studying, the effective use of learning strategies is central to adaptive learning. Pintrich (1989) defines learning strategies as the cognitive strategies or the ways of information processing that students use in studying or learning their lessons. In addition to purely cognitive strategies, such as cognitive rehearsal, elaboration, organization, and critical thinking, resource management strategies, such as time and effort regulation, are an important part of effective learning strategies. Another much-used distinction is between deep-level and surface-level learning (Entwistle and Entwistle, 1991; Nolen, 1988). Students who engage in deep-level learning are actively elaborating, structuring, and questioning the course materials to understand the underlying meaning. In contrast, students who stick to surface-level learning focus on memorization without understanding. They are mainly relying on rehearsal and other passive learning strategies. Although specific task situations may either inhibit or facilitate deep-level learning, learning styles are also thought to reflect (at least in part) more or less stable individual differences in learning styles (Biggs, 1993). Most importantly, the use of effective cognitive and self-regulative strategies predicts school achievement. In particular, deep-level learning and self-regulation are associated with enhanced school performance (Pintrich and De Groot, 1990).

Extending the research on motivation and learning to take into account FTP, Lens et al. (in press) found that when the present learning task is experienced as having high instrumentality or utility, students score higher on deep-level learning and lower on surface-level learning. Consequently, they are also achieving better school results than do their classmates who perceive a low utility value. Similar findings are also reported by Simons et al. (2003). Although perceived instrumentality may directly enhance classroom behavior through volition or self-control, it seems most likely that its motivational impetus is mediated by increased interest in classroom tasks or activities (Lens et al., in press).

In summary, research on FTP accentuates the added instrumental value, as distinct from the incentive value, of academic tasks in connection with future goals. Perceptions of instrumentality refer to the presence or absence of positive connections between immediate task goals and more or less distant future goals. Overall, the empirical findings discussed above support the following conclusions: students with a positive perception of the instrumentality of school work to reach future career goals (a) are more motivated for school tasks, (b) make more use of effective learning strategies, and (c) work harder and perform better in school. In contrast, ambivalent or 
negative perceptions of instrumentality are associated with lower levels of task motivation, less effective learning strategies, less persistence, and poor performance.

\section{Internal Regulation, Motivation, and Learning}

Since the introduction of goal theory, we know that not only the intensity or quantity of student motivation matters but also its quality. In educational settings, parallel distinctions are made between task goals and ego goals (Maehr, 1984), mastery and ability goals (Ames and Archer, 1988), learning and performance goals (Dweck, 1986), or task involvement and ego involvement (Nicholls, 1984), as distinct reasons to engage with schoolwork. Task-oriented students are primarily motivated to learn in order to increase their knowledge and competence. They want to improve on their past performance, to learn from their mistakes, to make progress over time, and to master ever more difficult or challenging tasks. In contrast, ego-oriented students are not so much motivated by the desire to learn new knowledge and skills as such. Rather, they perceive school tasks as opportunities to demonstrate ability, to outperform others, to achieve success (approach goals), or to avoid looking stupid or ignorant in front of their classmates (avoidance goals). In short, they are concerned more with self-worth or self-evaluation than with learning or problem solving. More in general, student goal orientations are the products of past personal experiences and present situational factors in the school environment (Ames and Archer, 1988). Typically, high levels of task orientation in students are associated with intrinsic (vs. extrinsic) motivation. In turn, task orientation or intrinsic motivation are related to positive motivational outcomes such as more effort and persistence, more effective learning strategies, and better school results (Dweck and Leggett, 1988; Elliot and Dweck, 1988; Nolen and Haladyna, 1990; Pintrich and De Groot, 1990). Conversely, ego orientation has often, though not always, been opposed to task orientation and associated with negative achievement outcomes (Harackiewicz et al., 1993; Pintrich, 2000).

Goal theories have mainly focused on immediate task goals. To include future goals into goal theories, research on intrinsic motivation and task orientation raises the following question: Does instrumentality preclude intrinsic interest and being task oriented? Indeed, to the extent that learning is motivated by future goals (instrumental motivation), it is not rewarding in itself. In this sense, instrumental motivation can only be extrinsic motivation. Along those lines, Eccles (1984) has contrasted utility value, which she defines as "the importance of (a) task for some future goal that might itself be somewhat unrelated to the process nature of the task at hand" 
(p. 90), with interest value, which she describes as "the inherent, immediate enjoyment one gets from engaging in an activity" (p. 89). In line with the classical definition of intrinsic motivation, she has contrasted utility value as extrinsic motivation with interest value as intrinsic motivation. If instrumental motivation is a type of extrinsic motivation, we need to know in what circumstances the utility value of performing well in school for one's future career undermines intrinsic task motivation, in the same way as extrinsic rewards sometimes do.

Two related lines of inquiry run counter to the extrinsic motivation thesis by connecting future goals with intrinsic motivation and task orientation. One argument refers to the distinct nature of task orientation as defined by goal theories. According to this definition, future orientation is an inherent feature of task orientation, with its typical goal stresses on making progress, looking for new challenges, and learning as an end in itself. In support of the forward-looking nature of task goals, the degree to which students value the future was positively related to their task goal focus for specific college courses (Husman and Lens, 1999). Another line of research distinguishes an endogenous type of utility of present tasks for future goals, which is associated with enhanced intrinsic motivation. The theoretical reasoning behind this notion of endogenous instrumentality draws links between types of instrumentality and levels of internal regulation or self-determination as distinguished by Deci and Ryan (1985; Deci et al., 1999). Within the domain of extrinsic motivation, so-called identified and integrated levels of regulation imply that goals are extrinsic to the task but that they are at the same time experienced as self-chosen, and hence internally controlled by the individual. The internal type of regulation is distinguished from so-called external and introjected levels of regulation, when goal setting is experienced as imposed from the outside, and hence externally controlled. Turning to FTP and instrumental motivation, so-called endogenous instrumentality is related to internal regulation. Thus, future goals may be at the origin of an internal type of regulation or self-determination, if they are experienced as self-set goals, and hence internally controlled, in spite of being extrinsic to the task.

Along those lines, Lens (2001; Lens and Rand, 1997) identified different types of instrumentality, or relations between present motivation and future goals. The typology is based on two dimensions. One dimension concerns the nature of present and future tasks or goals. If an academic task in the present belongs to the same motivational category as the relevant future task or goal, the relation between both tasks is endogenous (Husman and Lens, 1999). Specifically, the endogenous dimension of instrumentality depends on the kinds of competences required to accomplish a task now and in the future. The more the capacities or competences used in present and future tasks overlap, the higher should be the utility or instrumentality of the 
present task for achievement goals in the future (e.g., studying mathematics to become an engineer vs. to become a nurse). Another dimension of instrumentality refers to the kinds of conditions that regulate classroom behavior, including the kind of future goals or rewards that are anticipated. Future goals can internally or externally regulate classroom behavior. Thus, externally regulated behavior is motivated by future goals that originate outside the person, such as job requirements or material rewards. In contrast, internally regulated behavior is driven by motives that are internal to the person, such as one's personal development or life project. In sum, exogenous future goals that are perceived as externally controlling students' motivation fall into the category of extrinsic motivation. If the typology is valid, a predominant focus on this type of future goals will not enhance the quality of task motivation in the present, whereas an alternative focus on future goals that are endogenous and/or internally controlled will.

As expected, correlational as well as experimental research with nonminority students demonstrates that students' motivation, task orientation, and intrinsic interest are enhanced when they perceive an endogenous link between their present schoolwork and future career goals. Students who are striving for future goals that are closely modelled on the skills learned in present schoolwork show higher levels of intrinsic motivation in school. Moreover, students who experience future goals as self-set goals (internal regulation) are also more intrinsically motivated to achieve than those who perceive the future as externally controlled (external regulation). Finally, in line with expectations from goal theory, students who develop an intrinsic interest in school tasks also score higher on task orientation, persistence, and effort, and lower on positive and negative ego orientation (Lens et al., 2001; Shell and Husman, 2001; Simons et al., 2000).

In addition, not only does the motivational impact of internal regulation enhance intrinsic motivation and task orientation, but it also fosters the use of more effective learning strategies, leading to improved school performance. Lens et al. (in press) found that when the present learning task is experienced as internally regulated, students score higher on deep-level learning and lower on surface-level learning. This also explains why they outperform their classmates who feel externally regulated by imposed or externally controlled future goals. For a more extensive review of recent evidence, we refer to Simons et al. in this special issue. Again, the motivational drive that comes from internal regulation through self-set future goals may enhance academic behavior directly as well as indirectly through increased interest in academic tasks (Lens et al., in press).

Taken together, recent findings on internal and external types of instrumentality corroborate the following conclusions. Students who are motivated by highly valued and internally controlled future goals, as part of a 
personal life project, (a) are more intrinsically motivated for their school work, (b) use more effective learning strategies, and (c) work harder and achieve better results. Conversely, students who are motivated by externally controlled future goals, such as increased earnings or job qualifications, and those who attach little or no value to future goals or rewards, show lower levels of task motivation, less effective learning strategies, less persistence, and poor performance.

\section{Cross-Cultural Implications: Future Goals in Minority Students' School Careers}

In the previous paragraphs, we developed and documented the motivational processes that are associated with (a) the perceived instrumentality of school tasks for future goals and (b) the internal or external regulation of classroom behavior by future goals. Returning to the central issue of minority school achievement, the following remaining questions must be addressed: How valid is our conceptualization of future goals across cultures; and how well does it explain contradictory findings on the importance and impact of the future in minority students' school achievement?

Our starting point is the paradoxical cross-cultural evidence on the importance and impact of future goals in minority students' school careers. On the one hand, the immigrant optimism hypothesis has portrayed minority students as highly aspiring and achieving (Kao and Tienda, 1995). On the other hand, conflicting findings of underachievement in spite of high aspirations are attributed to the detrimental effects of limited opportunities and cultural discontinuities on minority students' school achievement (D'Amato, 1993; Mickelson, 1990). In light of the moderating role of perceived instrumentality and internal regulation in (dis)connecting school achievement with future goal setting, more fine-grained motivational concepts and measures are needed to improve our understanding of minority students' school careers. So far, research on minority students' school achievement that takes into account recent developments in research on FTP is limited. However, preliminary findings tend to support the cross-cultural validity and the explanatory power of the FTP framework in multicultural educational settings.

In particular, the experience of limited opportunities or cultural barriers in minority students' school careers may affect the instrumental value of school tasks, giving rise to ambivalent or negative perceptions of instrumentality. Thus, one possible explanation of more frequent school disengagement in minority youth is the failure to connect school engagement with valued future goals. Phalet et al. (2001) have put the negative instrumentality hypothesis to a test. They compared minority students and native 
youth in Dutch schools, using a questionnaire measure to categorize students into positive, negative, and ambivalent types of perceived instrumentality. In line with FTP research (cf. supra) and across cultures, positive perceived instrumentality is related to higher levels of task motivation. Although the evidence is correlational, the motivational impact of the perceived instrumental value of school tasks for future goals is robust after controlling for gender, parental education (low or higher), and school tracks (vocational or higher). As expected by the negative instrumentality hypothesis, minority youth have less positive and more ambivalent or negative perceptions of the instrumentality of doing well in school for their future than native youth. But gross motivational differences are completely accounted for by family background (parental education) and school track (vocational or higher). Apparently, unequal educational opportunities are a more plausible explanation of motivational differences between minority and native youth than cultural discontinuities per se.

In addition, there is yet another way in which unequal opportunities or cultural discontinuities may impede minority students' school achievement. In as far as future goals are perceived as out of reach (in the case of perceived discrimination) or externally imposed (in the case of experienced culture conflict), minority youth are more prone than native youth to experience future career goals as externally controlled and, hence, to disengage with learning. The external regulation hypothesis receives mixed support from correlational findings in multicultural classrooms. Concretely, Phalet et al. (2001) asked immigrant and native students to rate the importance (high or low) of internally and externally controlled types of future goals. On the basis of their ratings, students were assigned to three subgroups: either (a) no regulation (low value attached to future goals) or (b) external regulation (high value attached to external future goals only, e.g., job opportunities or earnings) or (c) internal regulation (high value attached to internal future goals as well, e.g., personal growth). In accordance with recent FTP research (cf. supra) and across cultures, internal regulation enhances student motivation, as well as adaptive learning (increased self-regulation and deep-level learning, decreased surface-level learning). But external regulation also contributes to task motivation. At the same time, only internal regulation, but not external regulation, was found to increase the use of effective learning strategies. Finally, and running counter to the external regulation hypothesis, minority youth are more motivated by internally controlled future goals than are native youth (e.g., they study to prepare themselves for a personal life project). In parallel, they also attach as much or more importance to external future goals (e.g., they want to improve their family's standard of living). Overall, minority students are more motivated by distant future goals than native students are. 
To conclude, the motivational effects of perceived instrumentality and types of regulation are largely replicated across cultures. Moreover, the paradoxical findings of motivational differences between minority and native students are explained at least in part by (a) more ambivalent or more negative perceptions of instrumentality among minority youth, together with (b) more internal as well as external regulation by distant future goals. These preliminary findings indicate new directions for cross-cultural research, extending the FTP approach to motivational explanations of minority students' school achievement. Moreover, they suggest the applied relevance of the FTP framework for enhancing task motivation and adaptive learning in multicultural classrooms.

\section{DISCUSSION}

This review brings together cross-cultural research in the United States and Europe on the motivational role of the future in multicultural classrooms. Overall, the analyses yield convergent results, which demonstrate the cross-cultural validity of our conceptualization of future goal setting, and which throw new light on conflicting findings of an impaired versus enhanced future orientation in ethnic minority students. Indeed, contradictory research findings on the schooling experience of minority youth were the starting point of this review. In general, future goals may help students to overcome momentary failures by focusing instead on the path toward future success. In minority students' school careers, a focus on future goals seems all the more important as a powerful protective factor against more frequent school failure and dropout.

Along those lines, the special relevance and decisive impact of future goals on minority students' school achievement are amply documented. Typically, minority families and youth show higher academic aspirations and future expectations than working-class native youth (Pels, 1998; Phalet and Claeys, 1993; Phalet and Schönpflug, 2001a,b; Zéroulou, 1998). Not only are minority families more aspiring, high academic aspirations in minority parents and children appear to enable sustained motivation in spite of repeated failure (Müller and Kerbow, 1993; Okagaki and Frensch, 1998; Phalet and Andriessen, in press; Vallet and Caille, 1996). Together, these cross-cultural findings corroborate the immigrant optimism hypothesis, which foregrounds family investment in education as a way to achieve upward mobility in the distant future (Kao and Tienda, 1995).

The immigrant optimism hypothesis has been challenged, however, by contradictory evidence from related lines of inquiry on minority underachievement due to blocked opportunities and/or cultural discontinuity. 
Thus, repeated findings of underachievement in spite of high aspirations have exposed the limits of future-oriented achievement motivation in the presence of structural disadvantage and discrimination (Mickelson, 1990; Ogbu and Simons, 1998). From a perceived opportunities perspective, disadvantaged minority youth are therefore expected and found to develop a more ambivalent orientation toward the future than native youth, which in turn interferes with minority students' school engagement and achievement (Fordham and Ogbu, 1986; Okagaki, 2001). From a complementary cultural-difference approach, similar predictions of an impaired future orientation and increased resistance to schooling among minority youth have been made. But explanations are sought primarily in the lack of cultural congruence between home and school environments (D'Amato, 1993; Jacob and Jordan, 1993; Okagaki, 2001). The detrimental motivational impact of cultural discontinuity should be qualified, however, as cooperative classrooms and supportive minority families can go a long way toward sustaining futureoriented achievement motivation in spite of disadvantage and discontinuity (Gibson, 2000; Okagaki, 2001; Phalet and Lens, 1995; Portes and MacLeod, 1996).

Much research on the schooling of minority youth has emphasized cultural difference or deficit over cross-cultural commonality. Consequently, the common motivational processes that connect family aspirations, cultural ideals, or personal goals in a distant future with classroom motivation and achievement are left largely unexplained. At the same time, new developments in research on FTP (cf. Nuttin and Lens, 1985) elucidate the cognitive-motivational processes that connect immediate task goals with delayed goals in the near or distant future. But most of this motivational research has not been validated across cultures, nor is it systematically applied to minority achievement in multicultural classrooms. Because the future figures prominently as a potential driving force in minority students' school careers, such a close link with research on future time perspective seems rather promising.

Specifically, we have theoretically elaborated and empirically documented two conceptual distinctions, which seem crucial to understanding how present task goals and future goals are (dis)connected through time: The first one is between incentive value and instrumentality; the second one is between internal and external types of regulation. First, educational research has often focused one-sidedly on the incentive value of immediate task goals. But doing well in school is not an end in itself. It is a future-oriented investment. Accordingly, the instrumentality of school tasks for realizing important future goals is shown to enhance task motivation, adaptive learning, and achievement (Creten et al., 2001; De Volder and Lens, 1982; Lens and Decruyenaere, 1991; Van Calster et al., 1991). Second, classroom behavior 
may be regulated by self-chosen or internally controlled future goals, or by future goals or rewards that are experienced as externally controlled. Recent research with nonminority students has associated internal regulation with enhanced intrinsic motivation and task orientation, and with effective learning strategies and performance (Deci and Ryan, 1985; Husman and Lens, 1999; Lens et al., 2001; Simons et al., 2000).

Linking up motivational research on FTP with minority students' school achievement, competing expectations of an impaired versus enhanced future orientation of minority students can be reformulated in a more precise way. Building on FTP research, there are two possible explanations for the failure of future goals to motivate school achievement in some minority (and native) youth. First, students may have ambivalent or negative perceptions of the instrumentality of doing well in school for success later in life (for instance, when they expect to be discriminated against by potential employers in spite of their qualifications, or when nonconventional or criminal careers appear more attractive ways to realize one's desired lifestyle). Second, students may experience future goals as externally controlled or imposed from the outside rather than internally driven or self-set goals (for instance, when they lack attractive coethnic role models of success in the host society, or when they feel that their future is determined by social forces outside their personal control).

Accordingly, there is preliminary evidence in support of the motivational importance and impact of future goals in minority students' school careers (Phalet et al., 2001; Phalet and Andriessen, in press). When school tasks are perceived as instrumental for future career goals, and especially when school work is internally regulated by future goal setting, minority and native youth alike show higher levels of task motivation, deep-level learning, and effective self-regulation. Conversely, positive perceptions of instrumentality and internal regulation effectively protect minority as well as native students against high risks of disengagement and maladaptive learning in multicultural classrooms. Although these empirical findings are encouraging, cross-cultural replications using the same fine-grained motivational measures in other multicultural settings is needed to further develop the FTP approach to minority students' school achievement.

From an applied educational perspective, the cross-cultural evidence reviewed in this article has great potential relevance for teaching practices in multicultural classrooms. In particular, many students to whom academic task goals have limited direct appeal are likely to profit from the added instrumental value by an extended FTP. Therefore, teachers should look for innovative ways of actively supporting the development of future goal setting in culturally diverse student populations, for instance, by stressing relevant future goals along with immediate task goals, or by articulating 
positive connections between making progress in class and achieving valued personal goals in the near and distant future.

\section{REFERENCES}

Ames, C., and Archer, J. (1988). Achievement goals in the classroom: Students' learning strategies and motivation processes. J. Educ. Psychol. 22: 269-298.

Andriessen, I., and Phalet, K. (2002). Acculturation and school success: A study among minority youth in the Netherlands. Intercultur. Educ. 13(1): 21-36.

Arroyo, C. G., and Ziegler, E. (1995). Racial identity, academic achievement and the psychological well-being of economically disadvantaged adolescents. J. Pers. Soc. Psychol. 69: 902-914.

Berry, J. W. (2002). Conceptual approaches to acculturation. In Chun, K. M., Organista, P. B., and Marin, G. (eds.), Acculturation: Advances in Theory, Measurement and Applied Research American Psychological Association, Washington, DC, pp. 17-37.

Biggs, J. (1993). What do inventories of students' learning processes really measure? A theoretical review and clarification. Br. J. Educ. Psychol. 63: 3-19.

Bovenkerk, F., Miles, R., and Verbunt, G. (1991). Comparative studies of migration and exclusion on the grounds of race and ethnic background in Western Europe. Int. Migr. Rev. 25: 375-391.

Clifton, R. A., Williams, T., and Clancy, J. (1991). The academic attainment of ethnic groups in Australia: A social-psychological model. Sociol. Educ. 64: 111-126.

Connell, J. P., Spencer, M. B., and Aber, J. L. (1994). Educational risk and resilience in African American youth: Context, self, action and outcomes in school. Child Dev. 65: 493506.

Creten, H., Lens, W., and Simons, J. (2001). The role of perceived instrumentality in student motivation. In Efklides, A., Kuhl, J., and Sorrentino, R. M. (eds.), Trends and prospects in Motivation Research, Kluwer Academic, Dordrecht, The Netherlands, pp. 33-45.

Crul, M. (1999). Explanations for school success of second generation Moroccan and Turkish youth in the Netherlands. In Crul, M., Lindo, F., and Pang, C. L. (eds.), Culture, Structure and Beyond, Spinhuis, Amsterdam, pp. 91-111.

D’Amato, J. (1993). Resistance and compliance in minority classrooms. In Jacob, E., and Jordan, C. (eds.), Minority Education: Anthropological Perspectives. Ablex, Norwood, NJ.

Day, J. D., Borkowski, J. G., Punzo, D., and Howsepian, B. (1994). Enhancing possible selves in Mexican-American students. Motiv. Emot. 18: 79-103.

Deci, E. L., Koestner, R., and Ryan, R. M. (1999). A meta-analytic review of experiments examining the effects of extrinsic rewards on intrinsic motivation. Psychol. Bull. 125: 627688.

Deci, E. L., and Ryan, R. M. (1985). Intrinsic Motivation and Self-Determination in Human Behavior, Plenum, New York.

De Volder, M. L., and Lens, W. (1982). Academic achievement and future time perspective as a cognitive-motivational concept. J. Personal. Soc. Psychol. 42: 566-571.

Dweck, C. S. (1986). Motivational processes affecting learning. Am. Psychol. 41: 1040-1048.

Dweck, C. S., and Leggett, E. L. (1988). A social-cognitive approach to motivation and personality. Psychol. Rev. 95: 256-273.

Eccles, J. (1984). Sex differences in achievement patterns. In Sonderegger, B. (ed.), Nebraska Symposium on Motivation: Vol. 32. Psychology and Gender University of Nebraska Press, Lincoln, pp. 97-132.

Elliott, E. S., and Dweck, C. S. (1988). Goals: An approach to motivation and achievement. J. Pers. Soc. Psychol. 54: 5-12.

Entwistle, N., and Entwistle, A. (1991). Contrasting forms of understanding for degree examinations: The student experience and its implications. Higher Educ. 22: 205-277.

Feather, N. T. (1982). Human values and the prediction of action: An expectancy-valence analysis. In Feather, N. T. (ed.), Expectations and Actions: Expectancy-Valence Models in Psychology, Erlbaum,Hillsdale, NJ, pp. 263-289. 
Fordham, S., and Ogbu, J. U. (1986). Black students'school success: Coping with the burden of acting white. Urban Rev. 18: 176-206.

Gailly, A. (1979). Vergelijkende studie van het tijdsperspectief bij Turkse en Vlaamse jongeren. [Comparative study of time perspective in Turkish and Moroccan youth], Internal report, Center for the Study of Motivation and Time Perspective, KU Leuven.

Gallimore, R. (1981). Affiliation motivation and Hawaiian-American achievement. Journal of Cross-Cult. Psychol. 5: 481-491.

Gibson, M. A. (2000). Situational and structural rationales for the school performance of immigrant youth: Three cases. In Vermeulen, H., and Perlmann, J. (eds.), Immigrants, Schooling and Mobility: Does Culture Make a Difference? MacMillan, Houndsmills, Great Brittain, pp. $72-102$.

Goodenow, C., and Grady, K. E. (1993). The relationship of school belonging and friends' values to academic motivation among urban adolescent students. J. Exp. Educ. 62: 60-71.

Greenbaum, P. E. (1985). Non-verbal differences in communication style between American Indian and Anglo elementary classrooms. Am. Educ. Res. J. 22: 101-115.

Harackiewicz, J. M., Barron, K., and Elliot, A. J. (1993). Achievement goals and intrinsic motivation. J. Person. Soc. Psychol. 65: 904-915.

Hieshima, J. A., and Schneider, B. (1994). Intergenerational effects on the cultural and cognitive socialisation of third- and fourth-generation Japanese Americans. J. Appl. Dev. Psychol. 15: 319-327.

Husman, J., and Lens, W. (1999). The role of the future in student motivation. Educ Psychol. 34: $113-125$.

Jacob, E., and Jordan, C. (eds.) (1993). Minority Education: Anthropological Perspectives. Ablex, Norwood, NJ.

Johnson, D. W., and Johnson, R. T. (1985). Motivational processes in cooperative, competitive and individualistic learning situations. In Ames, C., and Ames, R. (eds.), Research on Motivation in Education: Vol. 2. The Classroom Milieu Academic Press, New York, pp. 249287.

Jordan, C. (1984). Cultural compatibility and the education of Hawaiian children: Implications for mainland educators. Educ. Res. Quart. 8: 59-71.

Kagitcibasi, C. (1990). Family and socialisation in cross-cultural perspective. In Berman, J. (ed.), Nebraska Symposium on Motivation 1989, Cross-Cultural Perspectives, University of Nebraska Press, Lincoln, pp. 135-200.

Kao, G., and Tienda, M. (1995). Optimism and achievement: The educational performance of immigrant youth. Soc. Sci. Q. 76: 1-19.

Lafromboise, T., Coleman, H., and Gerton, J. (1993). Psychological impact of biculturalism: Evidence and theory. Psychol. Bull. 114: 395-412.

Lens, W. (1986). Future time perspective: A cognitive-motivational concept. In Brown, D. R., and Veroff, J. (ed.), Frontiers in Motivational Psychology Springer-Verlag, New York, pp. 173-190.

Lens, W. (2001). How to combine intrinsic task motivation with the motivational effects of the instrumentality of present tasks for future goals. In Efklides, A., Kuhl, J., and Sorrentino, R. (eds.), Trends and Prospects in Motivation Research Kluwer, Dordrecht, the Netherlands, pp. 37-52.

Lens, W., and Decruyenaere, M. (1991). Motivation and de-motivation in secondary education: Student characteristics. Learn. Instr. 1: 145-159.

Lens, W., and Rand, P. (1997). Combining intrinsic goal orientations with professional instrumentality/utility in student motivation. Pol. Psychol. Bull. 28: 103-123.

Lens, W., Simons, J., and Dewitte, S. (2001). Student motivation and self-regulation as a function of future time perspective and perceived instrumentality. In Volet, S., and Järvelä, S. (eds.), Motivation in Learning Contexts Pergamon, New York, pp. 233-248

Lens, W., Simons, J., and Dewitte, S. (in press). From duty to desire: The role of students' future time perspective and instrumentality perceptions for study motivation and self-regulation. In Pajares, F., and Urdan, T. (eds.), Adolescence and Education: Vol. 2. Academic Motivation of Adolescents, Information Age, Greenwich, CT. 
Maehr, M. L. (1984). Meaning and motivation: Personal investment. In Ames, R., and Ames, A. (eds.), Research on motivation in education: Vol. 1. Student Motivation, Academic Press, New York, pp. 115-143.

Maehr, M. L., and Nicholls, J. G. (1980). Culture and achievement motivation: A second look. In Warren, N. (ed.), Studies in Cross-Cultural Psychology: Vol. 2, Academic Press, New York, pp. 221-267.

Matute-Bianchi, M. E. (1986). Ethnic identities and patterns of school success and failure among Mexican-descent and Japanese-American students in a California highschool. Am. J. Educ. 95: 233-255.

Meece, J. L., and Kurtz-Costes, B. (2001). The schooling of minority children and youth. Educ. Psychol. 36(1): 1-8.

Mickelson, R. A. (1990). The attitude-achievement paradox among black adolescents. Soc. Educ. 63: 44-61.

Mischel, W. (1981). Objective and subjective rules for delay of gratification. In d'Ydewalle, G., and Lens, W. (eds.), Cognition in Human Motivation and Learning, Erlbaum, Leuven and Hillsdale, NJ, pp. 33-58.

Müller, C., and Kerbow, D. (1993). Parent involvement in the home, school and community. In Schneider, B., and Coleman, J. (eds), Parents, Their Children and Schools, Westview, Boulder, CO, pp. 13-42.

Nicholls, J. G. (1984). Conceptions of ability and achievement motivation. In Ames, R., and Ames, C. (eds.), Research on Motivation in Education: Vol. 1. Student Motivation, Academic, San Diego, CA, pp. 39-73.

Nijsten, (1998). Opvoeding in Turkse gezinnen in Nederland [Parenting in Turkish families within the Netherlands], Van Gorcum, Assen, The Netherlands.

Nolen, S. B. (1988). Reasons for studying: Motivational orientations and study strategies. Cogn. Instr. 5: 269-287.

Nolen, S. B., and Haladyna, T. M. (1990). Personal and environmental influences on students' beliefs about effective study strategies. Contemp. Educ. Psychol. 15: 116-130.

Nuttin, J., and Lens, W. (1985). Future time Perspective and Motivation: Theory and Research Method, Leuven University Press, Leuven, Belgium.

Ogbu, J. U. (1992). Understanding cultural diversity and learning. Educ. Res. 21(8), 5-14.

Ogbu, J. U., and Simons, H. D. (1998). Voluntary and involuntary minorities. A culturalecological theory of school performance with some implications for education. Anthropol. Educ. Quart. 29: 155-188.

Okagaki, L. (2001). Triarchic model of minority childen's school achievement. Educ. Psychol. 36: 9-20.

Okagaki, L., and Frensch, P. A. (1998). Parenting and children's school achievement: A multiethnic perspective. Am. Educ. Res. J. 35: 123-144.

Okagaki, L. Frensch, P. A., and Dodson, N. E. (1996). Mexican-American children's perceptions of self and school achievement. Hispanic J. Behav. Sci. 18: 469-484.

Pels, T. (1998). Opvoeding in Marokkaanse gezinnen in Nederland: de creatie van een nieuw bestaan [Parenting in Moroccan families in the Nethralnds], Van Gorcum, Assen, The Netherlands.

Phalet, K., and Andriessen, I. (in press). Acculturation, motivation and educational attainment: A contextual model of minority school achievement. In Hagendoorn, L., Veenman, J., and Vollebergh, W. (eds.), The Integration of Immigrants in the Netherlands, Ashgate, Aldershot, England.

Phalet, K., Andriessen, I., and Lens, W. (2001, August). Future goals, task motivation and learning: A cross-cultural study of Turkish, Moroccan and native Dutch students. $\mathrm{Pa}$ per presented at the American Psychological Association Conference, San Fransisco, CA.

Phalet, K., and Claeys, W. (1993). A comparative study of Turkish and Belgian youth. Journal of Cross-Cultural Psychol., 24: 319-343.

Phalet, K., and Hagendoorn, L. (1996). Personal adjustment to acculturative transitions: The Turkish experience. Int. J. Psychol. 31: 131-144. 
Phalet, K., and Lens, W. (1995). Achievement motivation and group loyalty among Turkish and Belgian youngsters. In Maehr, M. L., and Pintrich, P. R. (eds.), Advances in Motivation and Achievement: Vol. 9. Culture, Motivation and Achievement, JAI, Greenwich, Connecticut, pp. 31-72.

Phalet, K., and Schönpflug, U. (2001a). Intergenerational transmission of collectivism and achievement values in two acculturation contexts. J. Cross-Cultur. Psychol. 32(2): 186201.

Phalet, K., and Schönpflug, U. (2001b). Intergenerational transmission in Turkish immigrant families: Parental collectivism, achievement values and gender differences. J. Comp. Fam. Stud. 32(4): 489-504.

Phalet, K., and Swyngedouw, M. (in press). Immigrant and host acculturation and value orientations. In Vinken, H., Soeters, G., and Ester, P. (eds.), Comparing Cultures, Brill, Leiden, the Netherlands.

Phinney, J. S., Horenczyk, G., Liebkind, K., and Vedder, P. (2001). Ethnic identity, immigration and well-being: An interactional perspective. J. Soc. Issues, 57(3): 493-510.

Pintrich, P. (1989). The dynamic interplay of student motivation and cognition in the college classroom. In Ames, C., and Maehr, M. L. (eds.), Advances in Motivation and Achievement: Vol. 6. Motivation Enhancing Environments JAI, Greenwich, CT, pp. 117-160.

Pintrich, P. R. (2000). Multiple goals, multiple pathways: The role of goal orientation in learning and achievement. J. Educ. Psychol. 92: 44-555.

Pintrich, P. R., and De Groot, E. V.(1990). Motivational and self-regulated learning components of classroom academic performance. J. Educ. Psychol. 82: 33-40.

Portes, A., and MacLeod, (1996). Educational progress of children of immigrants: The roles of class, ethnicity and school context. Soc. Educ. 69: 255-275.

Roeser, R. W., Midgley, C., and Urdan, T. C. (1996). Perceptions of the school psychological environment and early adolescents' psychological and behavioral functioning in school. $J$. Educ. Psychol. 88(3): 408-422.

Schneider, B., and Lee, Y. (1990). A model for academic success: The school and home environment of East-Asian students. Anthropol. Educ. Q. 13: 308-322.

Shell, D. F., and Husman, J. (2001). The multivariate dimensionality of personal control and future time perspective beliefs in achievement and self-regulation. Contemp. Educ. Psychol. 26: 481-506.

Shih, M., Pittinsky, T. L., and Ambady, N. (1999). Stereotype susceptibility: Identity salience and shifts in quantitative performance. Psychol. Sci. 10: 80-83.

Slaughter-Defoe, D. T., and Rubin, H. H. (2001). A longitudinal case study of head start eligible children: Implications for urban education. Educ. Psychol. 36: 31-44.

Simons, J., Dewitte, S., and Lens, W. (2000). Wanting to have versus wanting to be: The effect of perceived instrumentality on goal orientation. Br. J. Psychol. 91: 335-351.

Simons, J., Dewitte, S., and Lens, W. (in press). “Don't do it for me. Do it for yourself!” Stressing personal relevance enhances motivation in physical education. J. Exerc. Sport Psychol.

Simons, J., Lens, W., Dewitte, S., and Vansteenkiste, M. (2003). Experimentally manipulated utility influences performance through motivated behavior. Educ. Psychol. Rev. 16: xxxxxx.

Smith, D. J., and Tomlinson, S. (1989). The School Effect: A Study of Multi-Racial Comprehensives, Policy Studies Institute, London.

Spencer, M. B., Noll, E., Stolzfus, J., and Harpalani, V. (2001). Identity and school adjustment: Revisiting the acting white hypothesis. Educ. Psychol. 36: 21-30.

Spencer, S. J., Steele, C. M., and Quinn, D. M. (1999). Stereotype threat and women's math performance. J. Exp. Soc. Psychol. 35: 4-28.

Steele (1997). A threat in the air: How stereotypes shape intellectual identity and performance. Am. Psychol. 52: 613-629.

Steele, C. M., and Aronson, J. (1995). Stereotype and the intellectual test performance of African Americans. J. Personal. Soc. Psychol. 69: 797-811.

Steinberg, L., Dornbusch, S. M., and Brown, B. B. (1992). Ethnic differences in adolescent achievement: An ecological perspective. Am. Psychol. 56: 723-729. 
Suarez-Orozco, C., and Suarez-Orozco, M. (1995). Transformation: Migration, Family and Achievement Motivation Among Latino Adolescents, Stanford University Press, Stanford, CA.

Tharp, R. G. (1989). Psychocultural variables and constants: Effects on teaching and learning in school. Am. Psychol. 44: 349-359.

Vallet, L.-A., and Caille, J.-P. (1996). Les élèves étrangers ou issues de l'immigration dans l'école et le collège francais. I/II/III. Documents de Travail INSEE/CREST, 9616/9614/9615.

Van Calster, K., Lens, W., and Nuttin, J. R. (1991). Affective attitude towards the personal future: Impact on motivation in high school boys. Am. J. Psychol. 100: 1-13.

Van de Vijver, F., and Phalet, K. (in press). Assessment in multicultural groups: The role of acculturation. Appl. Psychol. Int. Rev. 52.

Verkuyten, M., and Canatan, K. (in press). Ethnic relations and identification in multi-ethnic classrooms. In Hagendoorn, L., Veenman, J., and Vollebergh, W. (eds.), The Integration of Immigrants in the Netherlands, Ashgate, Aldershot, England.

Vermeulen, H., and Perlmann, J. (eds.) (2000). Immigrants, Schooling and Social Mobility: Does culture make a difference? MacMillan, London.

Voekl, K. E. (1996). Measuring students' identification with school. Educ. Psychol. Meas. 56: 760-770.

Yu, A.-B., and Yang, K.-S. (1994). The nature of achievement motivation in collectivistic societies. In Kim, U., Triandis, H. C., Kagitcibasi, C., Choi, S.-C., and Yoon, G. (eds.), Individualism and Collectivism: Theory, Method and Applications, Sage, Thousand Oaks, CA, pp. 239-250.

Zéroulou, Z. (1998). La réussite scolaire des enfants d'immigrés: L'apport d'une approache en termes de mobilisation. Revue Francaise de Sociologie, 29: 447-470. 